\title{
Study Kinerja ISD dengan Penambahan Sistem Kontrol Suhu Udara dan Kelembaban pada Pengeringan Gabah
}

\section{(ISD Performance Study with The Addition of Air Temperature and Humidity Control System on Drying Paddy Grain)}

\author{
Muliyani', Mustaqimah', Diswandi Nurba1* \\ 'Program Studi Teknik Pertanian, Fakultas Pertanian, Universitas Syiah Kuala \\ *Corresponding author: diswandinurba@unsyiah.ac.id
}

\begin{abstract}
Abstrak. Pengeringan padi menggunakan in-store dryer (ISD) memiliki keunggulan seperti kemudahan dalam pengendalian suhu dan tidak terpengaruh cuaca. Penambahan sistem kontrol pada ISD diharapkan dapat meningkatkan kinerja ISD serta menjaga kestabilan suhu dan RH selama pengeringan berlangsung. Metode penelitian ini dilakukan dengan mengeringkan $100 \mathrm{~kg}$ gabah menggunakan ISD dengan kadar air awal 17,77\%, yang dikeringkan hingga mencapai kadar air kering simpan (maks 14\%). Parameter yang dianalisis berupa suhu, kelembaban relatif $(\mathrm{RH})$, kecepatan aliran udara pengering, kadar air dan laju pengeringan. Hasil penelitian menunjukkan bahwa pemasangan sistem kontrol dapat mengendalikan dan mempertahankan suhu ISD agar selalu berada di atas suhu lingkungan dengan selisih sekitar $5,1^{\circ} \mathrm{C}$. Selain itu sistem kontrol juga dapat mengendalikan RH ISD agar lebih kecil dari RH lingkungan. Sistem kontrol juga mempengaruhi laju pengeringan, dimana laju pengeringan meningkat seiring meningkatnya kinerja sistem kontrol dalam mengendalikan suhu dan RH ISD.
\end{abstract}

Kata kunci : Pengeringan, In-Store Dryer, Sistem Kendali

Abstract. Drying paddy grain using an In-Store Dryer (ISD) has advantages such as ease of temperature control and is not affected by the weather. The addition of an ISD control system is expected to improve the ISD performance and maintain a stable temperature and $R H$ during the drying process. This research method was carried out by drying $100 \mathrm{~kg}$ of paddy grain using ISD with an initial moisture content of $17.77 \%$, dried to a storage dry moisture content (max 14\%). Parameters analyzed were temperature, relative humidity $(\mathrm{RH})$, drying airflow velocity, moisture content, and drying rate. The results showed that the installation of the control system could control and maintain the ISD temperature. It is always above the ambient temperature, with a difference of about $5.1^{\circ} \mathrm{C}$. In addition, the control system can also control the ISD RH to be smaller than the environmental RH. The control system also affects the drying rate, where the drying rate increases with the increase in the control system's performance in controlling ISD temperature and $\mathrm{RH}$.

Keywords: Drying, In-Store Dryer, Control System

\section{PENDAHULUAN}

Gabah merupakan sumber pangan paling utama di Indonesia dan beberapa negara lainnya. Permasalahan paling mendasar pada penanganan pasca panen gabah adalah tingginya susut pasca panen baik berupa susut kualitas maupun susut kuantitas, sehingga diperlukan suatu upaya penanganan pasca panen yang tepat untuk menekan susut panen dan mempertahankan mutu gabah (Butardo et al. 2019).

Menurut Wankhade et al. (2011) Pengeringan gabah dapat dilakukan dengan cara alamiah (penjemuran) ataupun cara buatan (artificial drying). Proses pengeringan gabah yang umum dilakukan oleh petani adalah dengan cara penjemuran, akan tetapi cara ini memiliki 
banyak kelemahan, yaitu selain membutuhkan lahan yang luas, tingkat susut hasil tinggi, resiko gabah basah karena hujan, maupun gabah kotor serta kesulitan dalam mengontrol suhu. Pengeringan gabah menggunakan alat pengering lebih efisien dibandingkan dengan pengeringan alami karena suhu pengeringannya lebih stabil sehingga meningkatkan laju pengeringan. In-Store Dryer (ISD) merupakan penggabungan sistem pengeringan dan penyimpanan yang menggunakan udara lingkungan yang dihembuskan ke tumpukan gabah padi yang akan dikeringkan (Nurba, 2016). Aplikasi Heat Exchanger yang digunakan untuk menginput udara panas ke dalam ruang ISD adalah dapat menaikkan suhu pengeringan dan menurunkan $\mathrm{RH}$ udara pengering, sehingga mengoptimalkan proses pengeringan gabah (Nurba, 2017).

Perubahan suhu dan kelembaban udara di lingkungan seringkali terjadi selama pengeringan yang menyebabkan suhu dan $\mathrm{RH}$ dalam ruang pengering tidak konstan sehingga perlu dikondisikan untuk mendapatkan performa pengeringan yang optimal. Penggunaan sistem kontrol pada alat pengering dapat memberikan solusi dalam mengurangi Fluktuasi suhu dan kelembaban udara. Sistem kontrol yang digunakan pada In-store Dryer menggunakan prinsip pengendalian kecepatan kipas untuk mengatur aliran udara yang memasuki ruang pengering.

\section{Rumusan Masalah}

Adapun rumusan masalah dari penelitian ini adalah bagaimana kinerja ISD dengan penerapan sistem kontrol aliran udara dalam proses pengeringan gabah

\section{Tujuan penelitian}

Penelitian ini bertujuan untuk mempelajari pengaruh penambahan sistem kontrol suhu udara dan kelembaban terhadap kinerja In-Store Dryer (ISD) pada pengeringan gabah.

\section{Ruang Lingkup Penelitian}

Ruang lingkup penelitian ini meliputi gabah $100 \mathrm{~kg}$ yang dikeringkan menggunakan In-Store Dryer (ISD) dengan input aliran udara, suhu dan RH terkendali.

\section{METODOLOGI PENELITIAN}

\section{Alat dan Bahan}

Alat yang akan digunakan dalam penelitian ini adalah alat pengering In-Store Dryer (ISD), Galah Sampel, Anemometer, hybrid recorder (CA), termocople, sistem kontrol suhu dan RH, Oven Drying, timbangan digital, Termometer (bola basah dan bola kering) laptop dan kamera. Bahan yang digunakan adalah arang dan gabah kering panen dari Aceh Besar sebanyak $300 \mathrm{~kg}$.

\section{Prosedur Penelitian}

Gabah sebanyak $100 \mathrm{~kg}$ dengan kadar air awal rata-rata 20-26\%, dikeringkan menggunakan ISD hingga mencapai kadar air kering simpan (maks 14\%). Selama pengeringan dilakukan pengamatan suhu, RH, kecepatan aliran udara dan penurunan kadar air yang berlangsung dari pukul 09:00 - 17:00 WIB. Pengambilan data suhu udara dan kelembaban dilakukan setiap 30 menit menggunakan sensor suhu dan $\mathrm{RH}$, serta hybrid recorder. Selama pengeringan gabah berlangsung, dilakukan pengendalian kecepatan aliran udara, suhu dan RH menggunakan sistem kontrol yang dipasang pada In-Store Dryer. Pengeringan gabah menggunakan In-Store Dryer dilakukan sebanyak 3 kali ulangan. Adapun 
mekanisme kerja dari sistem kontrol ini adalah dengan menggunakan sensor suhu dan RH untuk mengendalikan kecepatan aliran udara melalui kecepatan kipas pada proses pengeringan.

\section{Karakteristik Alat Pengering In-Store Dryer (ISD)}

In-store dryer (ISD) merupakan alat pengering dan penyimpanan yang memiliki bentuk seperti silo yaitu silinder yang dapat berfungsi sebagai ruang penyimpanan pasca pengeringan. Bangunan ISD memiliki tinggi $1,95 \mathrm{~m}$, dengan diameter $0,80 \mathrm{~m}$. Bangunan ISD ini dilengkapi dengan 14 buah pipa, yang terdiri dari 9 pipa input udara dan 4 pipa output udara. Pipa ini terbuat dari plat esser berpori galvanis dengan ketebalan 0,002 m. Pipa-pipa inilah yang berperan penting dalam mendistribusikan udara di dalam ISD (Nurba, 2008).
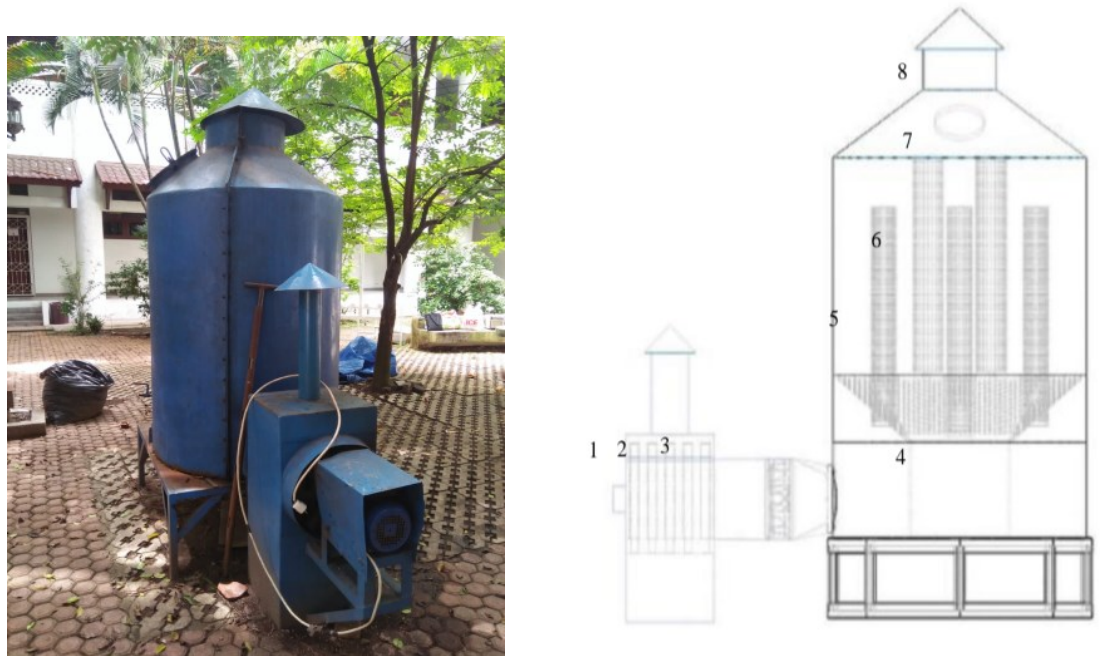

Keterangan:

1. Inlet Udara

2. Kipas

3. Heat Exchanger

4. Saluran Outlet biji-bijian

5. Pipa Input

6. Pipa Output

7. Pintu Kontrol

8. Outlet Udara

Gambar 1. Skema Bangunan ISD (Nurba, 2018)

\section{PEMBAHASAN}

\section{Distribusi Suhu pengeringan}

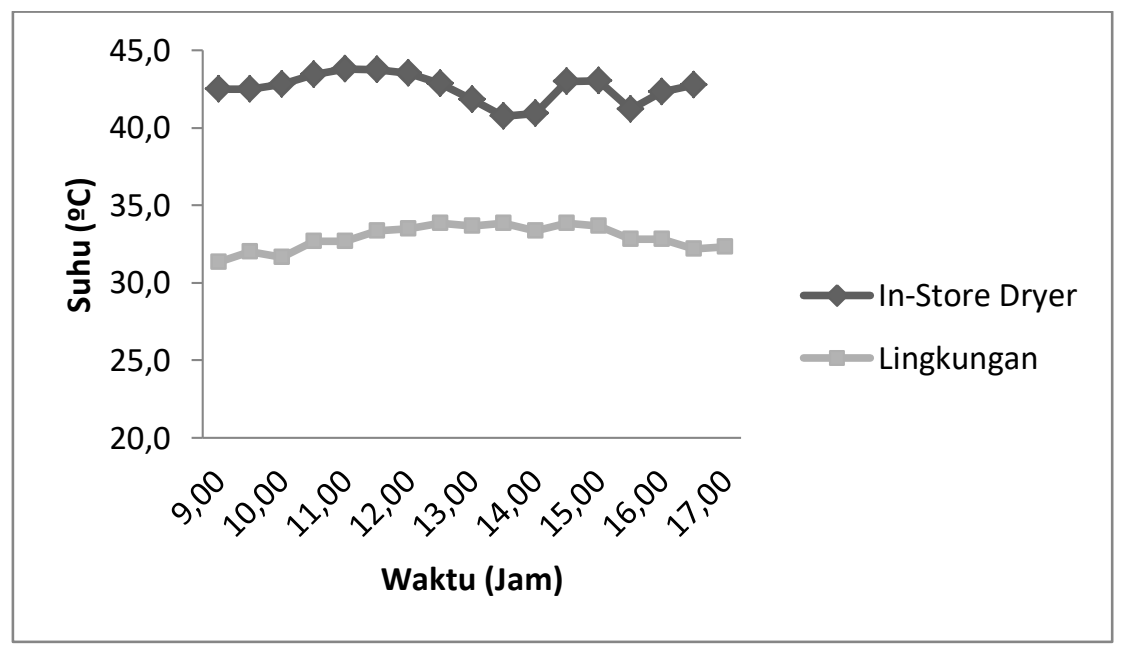

Gambar 2. Perbandingan Suhu Lingkungan dengan Suhu ISD 
Gambar 2 menunjukkan perbandingan suhu lingkungan dengan suhu ISD dan distribusi suhu di dalam ruang pengering ISD selama pengeringan gabah berlangsung. Selama pengeringan berlangsung, suhu di dalam ISD berkisar antara $33,3{ }^{\circ} \mathrm{C}$ sampai $40,1^{\circ} \mathrm{C}$. sedangkan suhu lingkungan berkisar antara $31{ }^{\circ} \mathrm{C}$ hingga $34,5{ }^{\circ} \mathrm{C}$. Pengeringan gabah dilakukan pada suhu rendah yaitu maksimal $40,1{ }^{\circ} \mathrm{C}$ agar dapat mempertahankan kualitas gabah yang sejalan dengan pendapat Trisnawati (2014) pengeringan pada suhu yang terlampau tinggi mengakibatkan gabah menjadi rusak dikarenakan cepatnya proses pengurangan kandungan air.

\section{Kelembaban Relatif (RH) pengeringan}

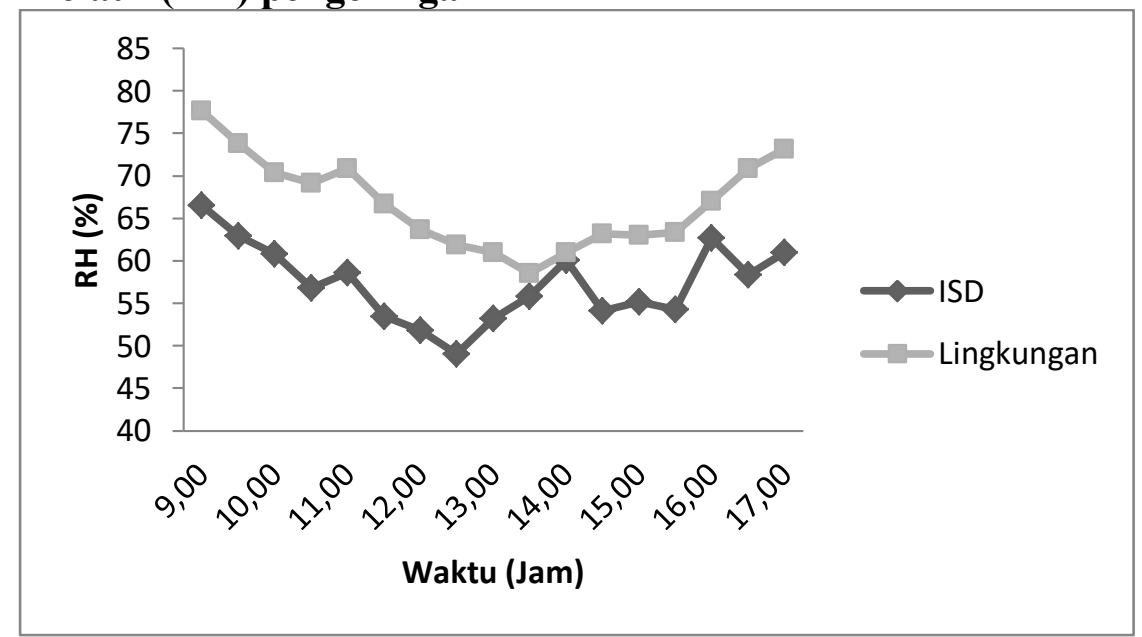

Gambar 3. Perbandingan RH ISD dengan RH Lingkungan

Gambar 3 menunjukkan bahwa rata-rata RH lingkungan selalu lebih tinggi daripada RH ISD. Dari gambar 3 dapat dilihat adanya fluktuasi yang kecil pada RH ISD ehingga pengeringan dapat tetap berjalan dengan baik. Fluktuasi ini terjadi akibat udara yang dihembuskan dari lingkungan yang melewati heat exghanger berfluktuasi. Namun demikian dengan adanya penambahan sistem kontrol suhu dan $\mathrm{RH}$, proses pengeringan yang dilakukan menjadi lebih efektif, dimana semakin tinggi suhu dan $\mathrm{RH}$ semakin rendah, maka waktu yang dibutuhkan untuk penguapan air dalam gabah juga semakin singkat. Kondisi tersebut sesuai dengan pernyataan Nurba et al., (2016), bahwa semakin kering udara pengeringan (RH semakin rendah) maka uap air yang diserap oleh udara akan semakin banyak sehingga laju pengeringan menjadi lebih cepat.

\section{Kecepatan Aliran Udara Pengeringan}

Kecepata aliran udara memiliki pengaruh besar terhadap proses pengeringan di dalam ISD. Udara yang mengalir di dalam ISD melalui tumpukan gabah dapat membawa uap air dari permukaan gabah sehingga dapat menurunkan $\mathrm{RH}$ di dalam ruang pengering agar tidak menghambat pengeringan gabah. 


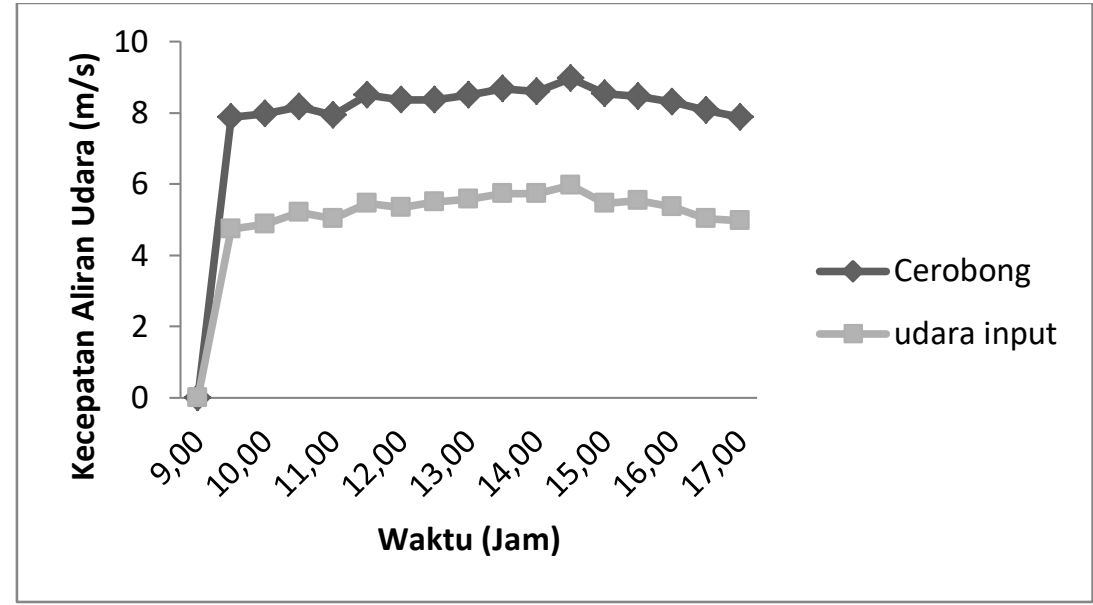

Gambar 4. Kecepatan Aliran Udara

Gambar 4. dapat diketahui bahwa kecepatan aliran udara dari cerobong dan udara input kipas tersebut tidak mengalami perubahan yang besar serta kecepatan aliran udara cerobong selalu lebih besar dari udara input kipas. Hal ini terjadi karena akumulasi aliran udara mengikuti bentuk bagian atas ISD yang mengecil pada cerobong sebagai outlet udara. Aliran udara paling cepat pada cerobong yaitu sebesar $9,2 \mathrm{~m} / \mathrm{s}$ sedangkan aliran udara tercepat pada input kipas sebesar $6,2 \mathrm{~m} / \mathrm{s}$.

\section{Kadar Air Gabah Selama Pengeringan}

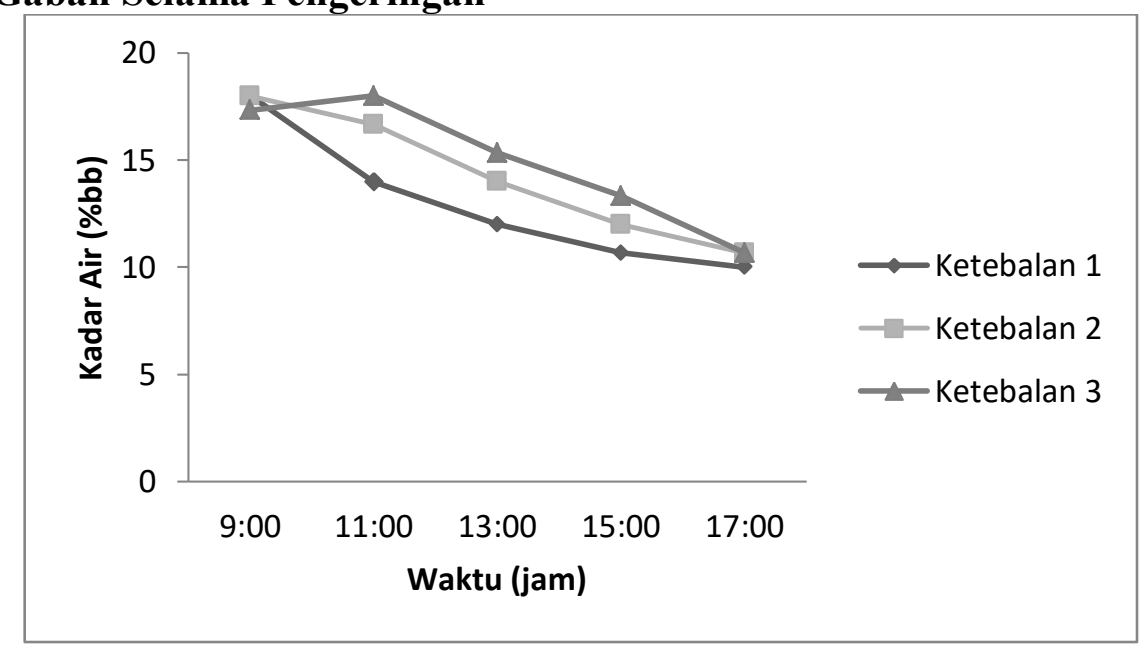

Gambar 5. Kadar air gabah selama perngeringan

Gambar 5. menunjukkan proses penurunan kadar air gabah di dalam ISD yang terjadi perlahan dimulai dari lapisan paling bawah hingga ke lapisan paling atas. Tumpukan gabah pada ketebalan 1 (1-10 cm dari lantai dasar ISD) mengalami penurunan kadar air paling cepat, hal ini dikarenakan tumpukan gabah pada bagian dasar lebih banyak menerima aliran udara serta udara menjadi jenuh uap air sehingga terbawa ke lapisan di atasnya. Menurut Nurba (2017), pada dasarnya pengeringan tumpukan tebal adalah proses pengeringan lapis tipis yang dikondisikan bertumpuk, maka uap air dari lapisan sebelumnya masih terkondensasi pada lapisan setelahnya tergantung pada suhu, RH dan kecepatan aliran udara yang membawa uap air tersebut. Hal ini mengakibatkan gabah pada ketebalan 3 (21-30 cm dari lantai dasar ISD) menjadi lapisan gabah yang paling terakhir kering. Sesuai dengan pernyataan Handayani (2014) dimana dalam suatu pengeringan tumpukan, lapisan yang terletak paling bawah lebih cepat mengalami penurunan kadar air yang dikarenakan sifat alami udara panas mengalir ke 
atas, sehingga udara panas beserta uap air akan terkumpul pada ruang pengering paling atas. Menurut Ramli (2017), Setelah diuapkan, air yang ada di dalam ruang pengering harus dipindahkan (dikeluarkan) melalui cerobong bersamaan dengan udara lembab. Gabah yang dikeringkan menggunakan ISD memiliki kadar air rata-rata 10,67\%.

\section{KESIMPULAN DAN SARAN}

Berdasarkan hasil dari penelitian yang telah dilakukan, maka dapat diambil beberapa kesimpulan sebagai berikut:

1. Penggunaan sistem kontrol suhu dan RH pada In-Store Dryer (ISD) dapat menjaga kestabilan suhu yaitu berkisar antara $33,3-40{ }^{\circ} \mathrm{C}$ dan $\mathrm{RH}$ diantara $42,1-75,3 \%$.

2. Laju pengeringan gabah menggunakan In-Store Dryer (ISD) dipengaruhi oleh sistem kontrol yang mensuplai aliran udara, suhu dan RH sesuai dengan kondisi suhu dan RH lingkungan.

3. Kadar air akhir gabah rata-rata setelah pengeringan dalam ISD didapatkan sebesar $10,67 \%$

\section{DAFTAR PUSTAKA}

Armita, D.Y. 2018. Karakteristik Pengeringan Dan Penyimpanan Gabah Menggunakan InStore Dryer. Skripsi. Universitas Syiah Kuala. Banda Aceh.

Butardo, V.M., N. Sreenivasulu, and B.O. Juliano. 2019. Improving Rice Grain Quality: State-of-the-Art and Future Prospects. In Rice Grain Quality (pp. 19-55).

Handayani,S.U., Rahmat, Darmanto,S. 2014. Uji Unjuk Kinerja Sistem Pengering Dehumidifier untuk Pengeringan Jahe. Jurnal Agritech. 34 (2): 232-238.

Nurba, D. 2008. Analisis Distribusi Suhu, Aliran Udara RH dan Kadar Air Dalam In-Store Dryer (ISD) untuk Biji Jagung. Tesis. Program Pascasarhana Institut Pertanian Bogor. Bogor.

Nurba, D., Agustina, R. 2017. Simulasi Perpipaan dalam In-store Dryer sebagai Pengering Konveksi untuk Biji Jagung. Universitas Syiah Kuala Press. Banda Aceh.

Nurba, D., Wulandari,D., Purwanto, Y.A., Paramawati,R., Nelwan, L.O., 2016. Analisi Sebaran Kadar air Jagung Selama Proses Pengeringan Dalam In-Store Dryer (ISD). Rona Teknik Pertanian. 9 (1) : 11-24.

Nurba, D., Agustina, R., Khatir, R., 2018. Laju Pengeringan Jagung Dalam In-Store Dryer Termodifikasi Dengan Heat Exchanger Dan Tungku Biomassa. Prosiding Seminar Nasional PERTETA : 66-72.

Ramli, I.D., Jamaluddin., Yanto, S. 2017 Laju Pengeringan Gabah Menggunakan Pengering Tipe Efek Rumah Kaca (ERK). Jurnal Pendidikan Teknologi Pertanian, Vol. 3. S158-S164.

Taheri-Garavand, A., Rafiee, S., Keyhani, A., 2011. Mathematical Modeling of Thin Layer Drying Kinetics of Tomato Influence of Air Dryer Conditions. Appl. Sci. 2, 14.

Wankhade, P.K., R.S. Sapkal dan V.S. Sapkal. 2013. Drying characteristics of okra slices on drying in hot air dryer. Procedia Engineering. 51:371-374. 